\title{
SIMULTANEOUS BILATERAL TEAR OF THE KNEE EXTENSOR MECHANISM IN A PRE-ADOLESCENT: CASE REPORT
}

Rodrigo Pires e Albuquerque', Vincenzo Giordano², Maria Isabel Pires e Albuquerque ${ }^{3}$, Antonio Carlos Pires Carvalho ${ }^{4}$, Ney Pecegueiro do Amaral ${ }^{5}$, João Maurício Barretto ${ }^{6}$

\section{ABSTRACT}

Unilateral tearing of a patellar tendon and a contralateral sleeve fracture in a pre-adolescent are rare lesions. We report a case in which a pre-adolescent sustained a fall while jumping during a soccer match. No predisposing risk factors were identified. The injuries were treated with surgical repairs and transosseous suturing. The aim of this study was to present a case of spontaneous concurrent tearing of the extensor mechanism of the knee in a pre-adolescent.

Keyword - Patellar Ligament; Knee; Rupture, Spontaneous; Adolescence

\section{INTRODUCTION}

Tearing of the patellar tendon is a well-known injury in the orthopedic literature. However, bilaterality is unusual and rarely reported in pre-adolescent children. In the immature skeleton, the most frequent lesion in the proximal region is the sleeve fracture, while in the distal region, avulsion of the tibial tuberosity is seen ${ }^{(1)}$. Bilateral tearing of the patellar tendon has been correlated with chronic systemic diseases.

In the present study, we report a case of simultaneous bilateral tearing of the knee extensor mechanism in a pre-adolescent and the therapy adopted.

\section{CASE REPORT}

A healthy 11-year-old boy suffered a fall following a jump in a soccer game and immediately presented pain, hemarthrosis and incapacity to walk (Figure 1). The patient was sent to the emergency service of our hospital. Physical examination revealed bilateral edema in the knees, high patella and a gap at the lower pole of the patella. He was also incapable of actively extending his leg. At the time of the trauma, the patient weighed $58 \mathrm{~kg}$ and his height was $1.60 \mathrm{~m}$.

Radiographs on the knees showed high patella, thus confirming the diagnosis of tearing of the patellar tendon on the right side and sleeve fracture on the left side. The patient's clinical history was investigated and blood tests for all the markers for rheumatic and renal diseases were performed, and all relationships with any systemic disease or steroid use were dismissed.

Surgery was performed one day after hospitalization, using a tourniquet and straight anterior incisions in the knees. The surgical technique used was suturing of the patellar tendon using transosseous perforations, without the need for reinforcement in either knee, since these were acute traumatic injuries. The suture repairs were tested by means of careful flexion of the knee joint (Figures 2 and 3).

After the operation, both knees were immobilized with a long knee immobilizer for six weeks. This was

\footnotetext{
1 - MSc and PhD in Medicine; Orthopedist and Coordinator of the Knee Surgery Sector, SOT-HMMC, Rio de Janeiro, RJ, Brazil.

2 - MSc in Medicine; Orthopedist and Coordinator of the Medical Residence Program, SOT-HMMC, Rio de Janeiro, RJ, Brazil.

3 - Pediatrician at the National Cancer Institute, Rio de Janeiro, RJ, Brazil.

4 - Associate Professor in the Department of Radiology, Federal University of Rio de Janeiro, Rio de Janeiro, RJ, Brazil.

5 - MSc in Medicine; Head Physician at SOT-HMMC, Rio de Janeiro, RJ, Brazil.

6 - MSc and PhD in Medicine; Head of the Orthopedics Service, Santa Casa do RJ, Rio de Janeiro, RJ, Brazil.

Work performed in the "Professor Nova Monteiro" Orthopedics and Traumatology Clinic, Miguel Couto Municipal Hospital (SOT-HMMC), Rio de Janeiro, RJ, Brazil. Correspondence: Av. Henrique Dodsworth 83, ap. 105, Copacabana, 22061-030 Rio de Janeiro, RJ, Brazil. E-mail: rodalbuquerque@ibest.com.br Work received for publication: July 28, 2011; accepted for publication: October 4, 2011.
}

The authors declare that there was no conflict of interest in conducting this work 


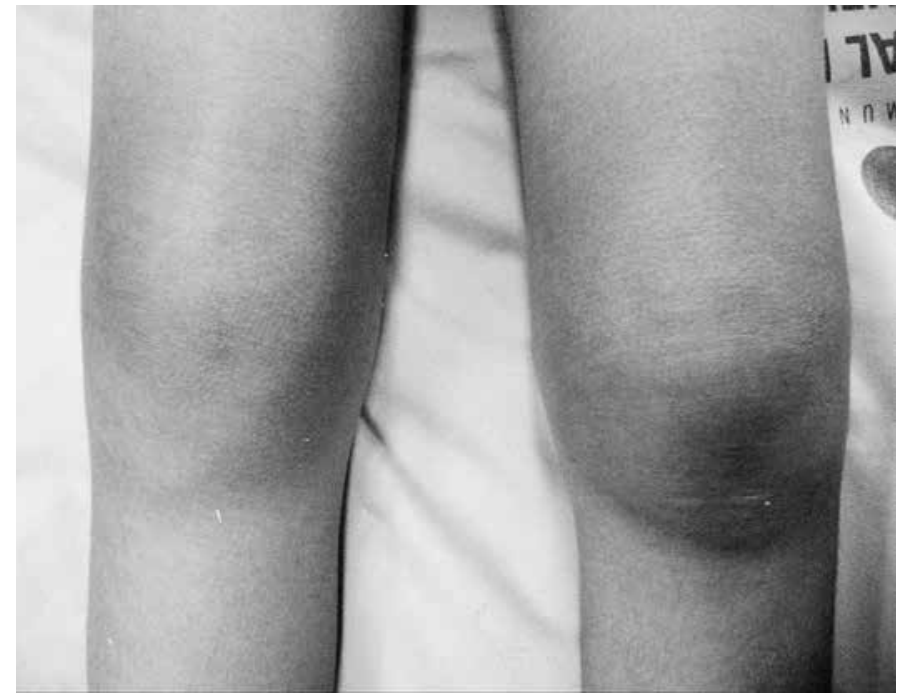

Figure 1 - Bilateral hemarthrosis of the knee.

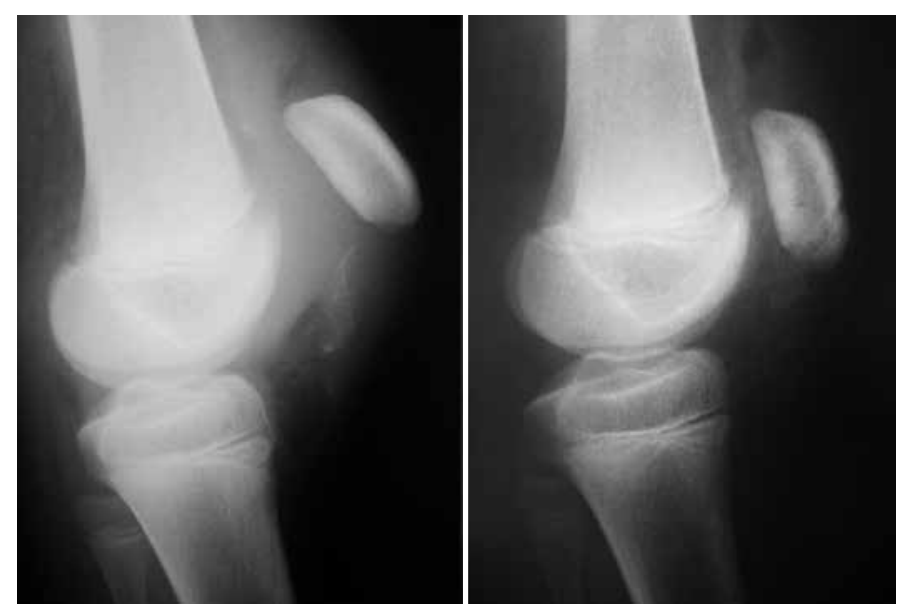

Figure 2 - Pre and postoperative radiographs on the left knee.
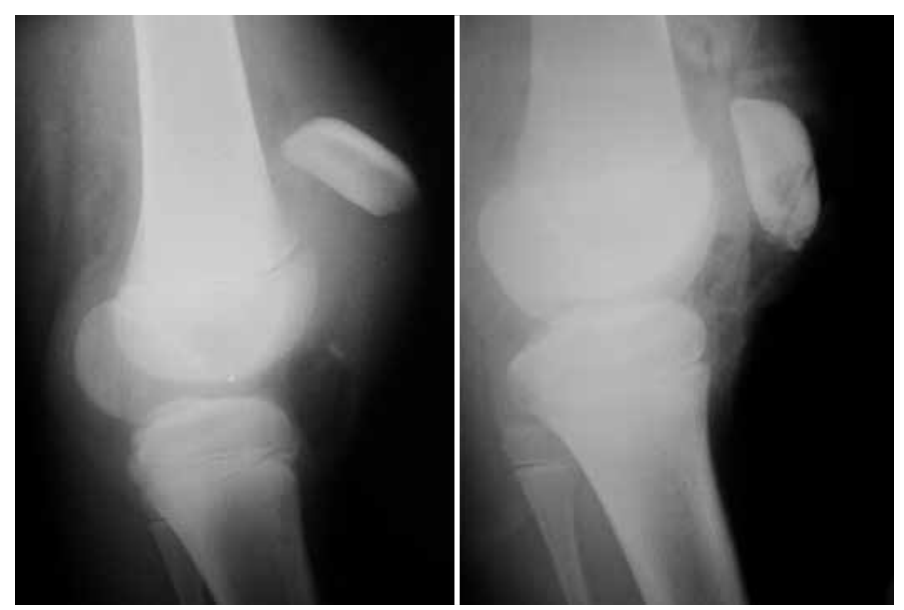

Figure 3 - Pre and postoperative radiographs on the right knee.

removed for active rehabilitation exercises in order to avoid atrophy of the quadriceps. The program consisted of isometric exercises for the quadriceps during the immobilization period and active exercises for the quadriceps with progressive increase of the range of movement. Complete range of motion and fully functioning knees were achieved after four months.

Our patient was assessed one week, 15 days, one month, 45 days and two months after the operation and then monthly until the sixth month, when the consultations became quarterly. Our follow-up of this patient has now reached two years, and he had gone back to his habitual activities, while continuing the follow-up with radiological control examinations, to evaluate the height of the patella and knee function using the modified Lysholm classification score ${ }^{(2)}$. The mean scores obtained are 92 and 94 points, respectively, which are considered to be excellent means using this system of evaluation.

\section{DISCUSSION}

In our case report, the sex affected was male, which corroborates reports in the literature regarding predominance of cases among males, in relation to females $(14 / 1)^{(3)}$.

In the immature skeleton, the muscles, ligaments and tendons are generally stronger than the growth plates. For this reason, it is rare to observe tearing of the substance of the tendon in children or adolescents. It has been estimated that a force of 17.5 times the body weight is needed to cause tearing of the patellar tendon in healthy individuals ${ }^{(4)}$. In our patient, injuries to the lower pole of the patella were observed in both knees, with hemarthrosis of the knees, thus showing the traumatic and acute nature of the injuries.

From reviewing the literature for English-language published papers on simultaneous bilateral tearing of the knee extensor mechanism in an immature skeleton, we only found two articles. This demonstrates the rarity of this injury and importance of our case report $^{(5,6)}$. Our case was the first to show tearing of the patellar tendon on one side and a sleeve fracture on the other.

There has been an investigation on structural alterations in the tendon resulting from microtrauma or tendon degeneration, thereby causing traumatic tearing ${ }^{(7)}$. On the other hand, other researchers have suggested that direct trauma on the knee could cause patellar injury in healthy patients ${ }^{(8)}$. In our study, because the patient was a pre-adolescent without previous complaints or systemic diseases, we believe that the injury mechanism was direct trauma, as cor- 
roborated by Cree et $a l^{(9)}$. Nonetheless, we agree that structural alterations increase the risk of lesions of the knee extensor apparatus.

In our view, the diagnosis of patellar tendon injury is basically clinical, achieved by means of palpation of the gap. With regard to complementary examinations, radiography on the knee (trauma series) provides good accuracy for diagnostic confirmation, as well as being a low-cost method. We did not use ultrasonography because this is an examiner-dependent test. Magnetic resonance imaging is a high-cost examination that is beyond the realities of some hospitals in Brazil. However, as this becomes a more widely used examination, it will contribute greatly towards analyzing the condition of the tendon and the structures surrounding the knee.

Early diagnosis and repair of the injury are the secret for success (Figures 4 and 5). We did not use reinforcement from the semitendinosus, cerclage with a steel wire or graft bank tissue because this was an acute injury of the knee extensor mechanism. We prefer to use these techniques when we are treating chronic lesions of the patellar tendon. Muratli et $a l^{(6)}$ performed injury repair using cerclage with a steel wire in association with graft bank tissue. Our thinking in this regard is that the steel wire would have to be removed in a second surgical procedure, thus giving rise to emotional stress in this pre-adolescent. Moreover, in relation to using tissue from a graft bank, there is a risk of disease transmission. Kim et $a l^{(5)}$ used anchors to repair the patellar tendon, claiming that this technique provided better quality than seen with the traditional method. However, we observed that in a comparative study in the literature, between these two surgical techniques, there was no difference in the repair failure rate ${ }^{(10)}$.

\section{REFERENCES}

1. Dedmond BT, Patterson L, McBryde A Jr, Kirol BG. Repeat patellar tendon rupture in a child. Am J Orthop (Belle Mead NJ). 2005;34(10):501-4.

2. Tegner $Y$, Lysholm J. Rating systems in the evaluation of knee ligament injuries. Clin Orthop Relat Res. 1985;(198):43-9.

3. Kellersmann R, Blattert TR, Weckbach A. Bilateral patellar tendon rupture without predisposing systemic disease or steroid use: a case report and review of the literature. Arch Orthop Trauma Surg. 2005;125(2):127-33.

4. Zernicke RF, Garhammer J, Jobe FW. Human patellar-tendon rupture. J Bone Joint Surg Am. 1977;59(2):179-83.

5. Kim JR, Park H, Roh SG, Shin SJ. Concurrent bilateral patellar tendon rupture in a preadolescent athlete: a case report and review of the literature. J Pediatr Orthop B. 2010;19(6):511-4.

6. Muratli HH, Celebi L, Hapa O, Biçimoğlu A. Bilateral patellar tendon rupture in a

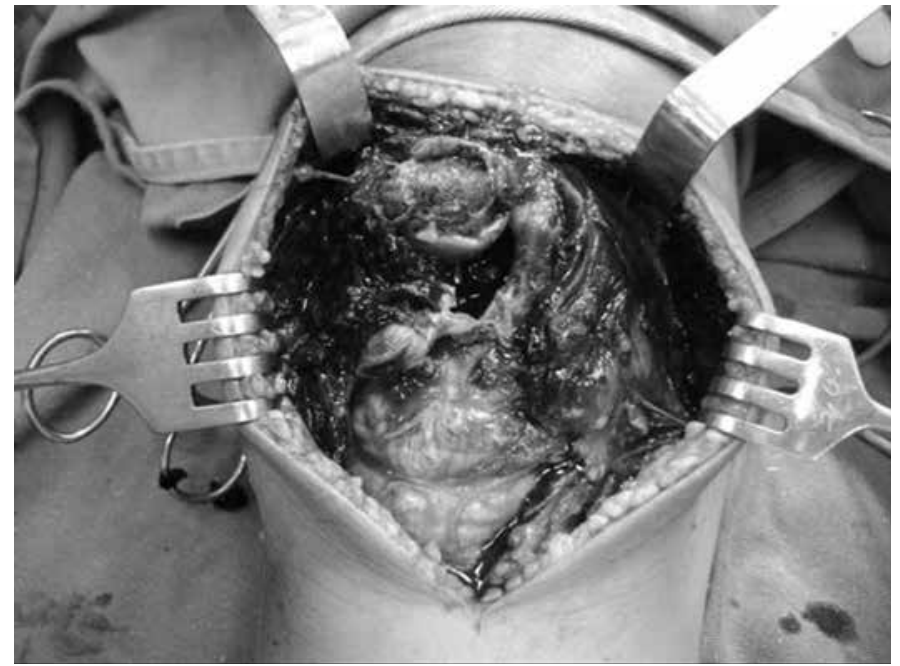

Figure 4 - Intraoperative view of the left knee.

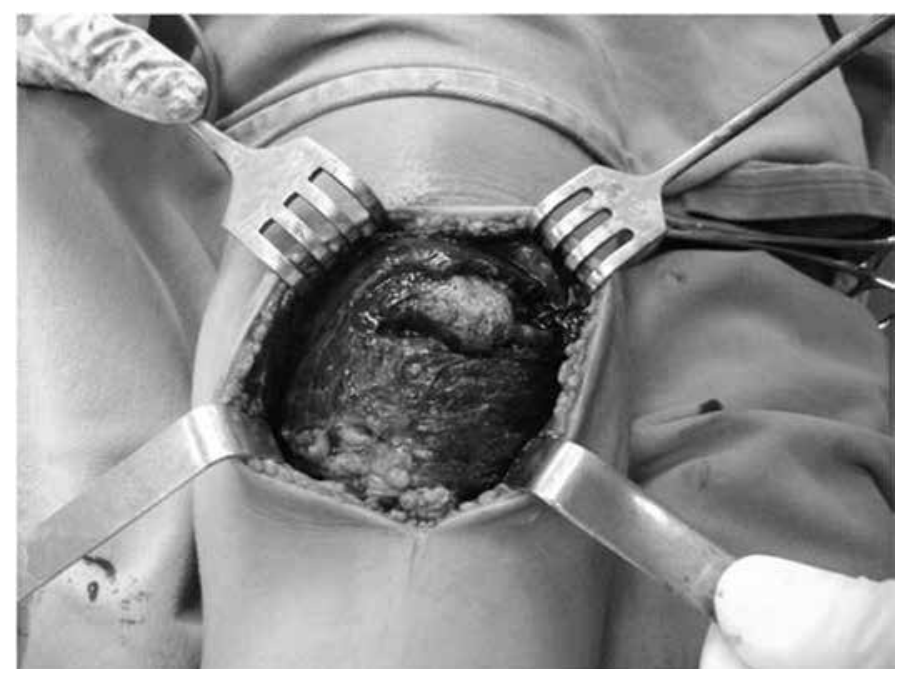

Figure 5 - Intraoperative view of the right knee.

Simultaneous bilateral tearing of the extensor mechanism in a pre-adolescent is an extremely rare injury. Our patient has been followed up for two years after the operation, with an excellent result according to the modified Lysholm scoring system. child: a case report. Knee Surg Sports Traumatol Arthrosc. 2005;13(8):677-82.

7. Kannus $P$, Józsa L. Histopathological changes preceding spontaneous rupture of a tendon. A controlled study of 891 patients. J Bone Joint Surg Am. 1991;73(10):1507-25.

8. Quintero Quesada J, Mora Villadeamigo J, Abad Rico JI. Spontaneous bilateral patellar tendon rupture in an otherwise healthy patient. A case report. Acta Orthop Belg. 2003;69(1):89-92.

9. Cree C, Pillai A, Jones B, Blyth M. Bilateral patellar tendon ruptures: a missed diagnosis: case report and literature review. Knee Surg Sports Traumatol Arthrosc. 2007;15(11):1350-4.

10. Bushnell BD, Byram IR, Weinhold PS, Creighton RA. The use of suture anchors in repair of the ruptured patellar tendon: a biomechanical study. Am J Sports Med. 2006;34(9):1492-9. 